\title{
Pneumorrhachis causing cauda equina syndrome: a case report and literature review
}

\author{
Areez Shafqat ${ }^{1}$, Hamzah M. F. Magableh', Shameel Shafqat ${ }^{2}$ and Syed Shafqat UI Islam ${ }^{3^{*}}$ (D)
}

\begin{abstract}
Background: Pneumorrhachis (PR) describes the rare presence of intraspinal air, mainly following traumatic or iatrogenic procedures. According to the localization of air in the spinal canal, PR has been classified into internal (subdural) and external (epidural). PR rarely manifests in neurological deficits and usually resolves spontaneously without recurrence, with air being passed directly into the bloodstream.

Here, we report a case of external PR occurring spontaneously (without any underlying trauma or surgical interventions) manifesting as neurological deficits. This is an extremely rare finding with only a limited number of cases in the literature.

Case presentation: We report a case of spontaneous external PR manifesting as neurological symptoms in a 62year-old male diabetic patient with chronic low backpain who developed numbness in his perineal region mainly on the left side. His medical history was normal, without trauma or surgical intervention. Magnetic resonance imaging (MRI) and computed tomography (CT) in the past 2 years demonstrated degenerative changes in the lumbar spine, including end plates and disc spaces, with intervertebral disc vacuum phenomenon (VP); the CT additionally showed intraspinal air in the epidural space at L5-S1 levels compressing the cauda equina. A diagnosis of spontaneous external PR was made. A follow-up MRI upon exacerbation of neurological deficits showed an increase in air locule size. Our patient was managed conservatively on a nonsteroidal anti-inflammatory agent (NSAI D) and was advised for regular follow-ups. No aspiration or surgery has been performed to date.

Conclusions: Spontaneous external pneumorrhachis manifesting as neurological symptoms is extremely rare. Due to degenerative disc disease producing vacuum phenomenon, we propose that spontaneous PR secondary to intradiscal VP be considered as part of the differential for radicular symptoms, especially with increasing age. The most effective noninvasive investigation for the diagnosis of PR is CT. MRI is less beneficial in the case of PR as gas and calcifications are hard to distinguish, both being of low-intensity signals on all MR sequences.
\end{abstract}

Keywords: Cauda equina syndrome, Intraspinal air, Pneumorrhachis, Spontaneous pneumorrhachis, Vacuum phenomenon

\footnotetext{
* Correspondence: drssislam@hotmail.com

${ }^{3}$ Department of Radiology, King Salman Hospital, Riyadh, Kingdom of Saudi

Arabia

Full list of author information is available at the end of the article
}

(c) The Author(s). 2020 Open Access This article is licensed under a Creative Commons Attribution 4.0 International License, which permits use, sharing, adaptation, distribution and reproduction in any medium or format, as long as you give appropriate credit to the original author(s) and the source, provide a link to the Creative Commons licence, and indicate if changes were made. The images or other third party material in this article are included in the article's Creative Commons licence, unless indicated otherwise in a credit line to the material. If material is not included in the article's Creative Commons licence and your intended use is not permitted by statutory regulation or exceeds the permitted use, you will need to obtain permission directly from the copyright holder. To view a copy of this licence, visit http://creativecommons.org/licenses/by/4.0/. 


\section{Background}

Pneumorrhachis (PR) is an exceptional finding characterized by the presence of intraspinal air following a multitude of possible etiologies, mainly trauma and iatrogenic procedures. Traumatic PR is often associated with air distribution in other body cavities, predominantly pneumocephalus, pneumothorax, pneumomediastinum, and subcutaneous emphysema. Therefore, the presence of traumatic PR necessitates searching for other pathological conditions to rule out the more untoward etiologies [1-3]. On rare occasions, PR develops spontaneously due to malignancy, violent coughing, and degenerative processes $[1$, 4]. PR is primarily a radiological diagnosis, with CT being the diagnostic tool of choice [4].

Based on the anatomic location of intraspinal air, PR is classified into extradural (external PR) and subdural (internal PR): extradural PR is generally innocuous, whereas internal PR is associated with major trauma and is believed to be a marker of severe injury [1]. In either case, PR is usually asymptomatic and resolves spontaneously without recurrence as air is directly passed into the bloodstream; thus, a conservative treatment approach is recommended $[1,4]$. Very rarely has PR been shown to manifest clinically as motor and sensory loss. We present the imaging findings of an extradural PR manifesting in neurological deficits and review the existing literature surrounding these findings.

\section{Case presentation}

A 62-year-old male diabetic patient with a history of chronic low backpain presented with the chief complaint of numbness in his perineal region mainly on the left side. No bowel or urinary symptoms were noted. There was no history of recent or past trauma, prior spinal injections, or surgery.

Upon MRI and CT in 2018 and 2019 respectively, degenerative changes in the lumbar spine were observed, including end plates and discs, with associated intervertebral disc space vacuum phenomenon (Fig. 1). CT additionally showed an air locule present in the epidural space at L5-S1 levels (Fig. 1). A diagnosis of external pneumorrhachis was made.

A follow-up MRI performed in May 2020 upon exacerbation of pain symptoms revealed an increase in the size of the air locule, measuring $1.5 \times 2 \mathrm{~cm}$ posterocentrally and in the left paramedian location at L5-S1 levels, compressing the cauda equina (Fig. 2). The other disc-related changes with mild bilateral foraminal compressions at multiple levels were relatively stable in comparison to previous imaging findings (Fig. 2).

Our patient was managed conservatively on a nonsteroidal anti-inflammatory agent and was advised for regular follow-ups. No aspiration or surgery has been performed to date.

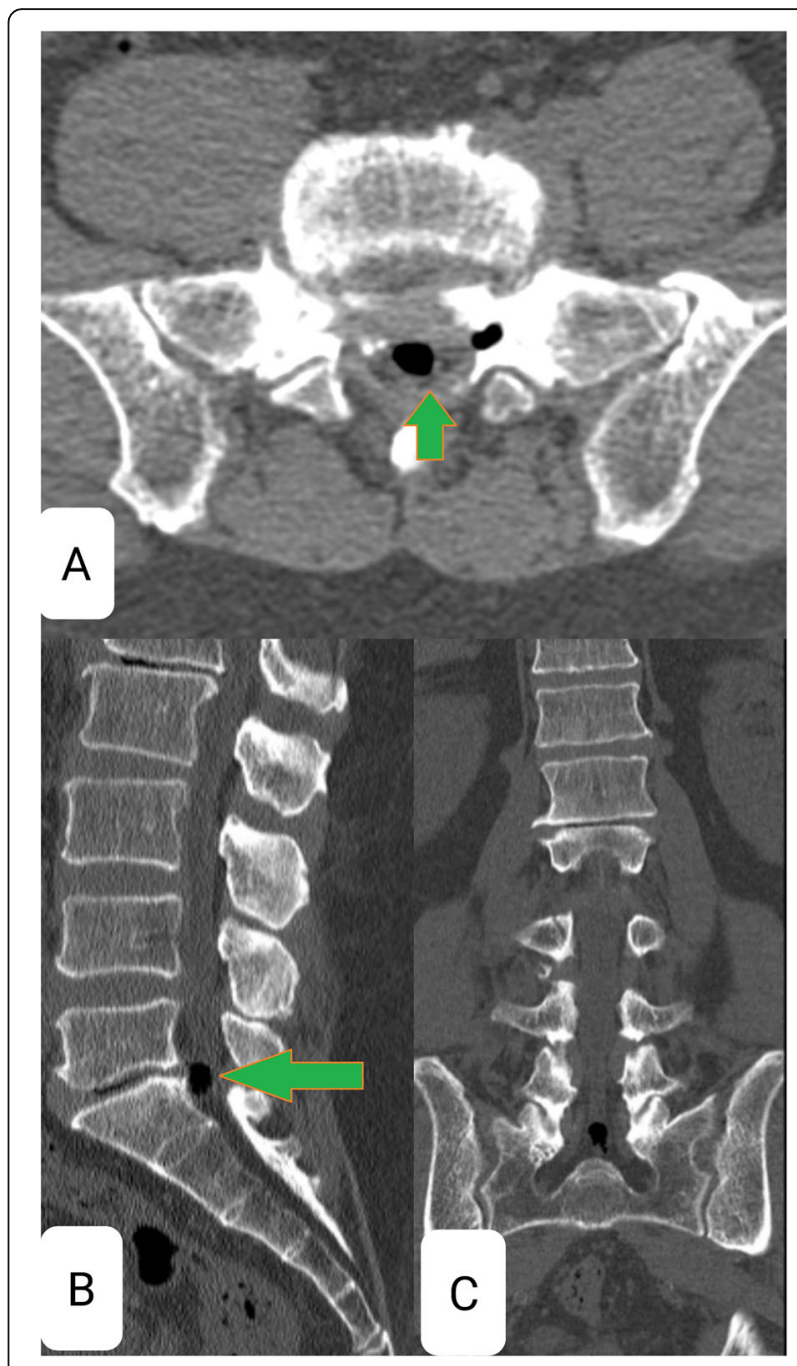

Fig. 1 CT scan. Axial (a), sagittal (b), and coronal (c) CT scan images reveal degenerative changes in the lumbar spine and vacuum phenomenon at L1-2 and L5-S1 levels, with facet joint degenerative changes in L5-S1 level. There is an air density seen in the intraspinal region at L5-S1 level. Reduced intervertebral disc space seen at L1-2 and L5-S1 levels. Origin: ๑ Department of Radiology, King Salman Hospital, Riyadh, Kingdom of Saudi Arabia, 2020

\section{Discussion}

In our case, external PR developed spontaneously, with imaging findings showing gas in the intervertebral disc secondary to degenerative disc disease. The radiographic appearance of gaseous collections in the disc space is called the vacuum phenomenon (VP), which largely occurs secondary to disc degeneration. From a biomechanical perspective, enlarging clefts in the disc create negative pressures which pull gas (produced from surrounding tissues) into the disc space $[5,6]$. PR can be produced from the vacuum disc phenomenon via 2 mechanisms: (1) gascontaining disc fragments herniate into the spinal canal, clinically presenting as a classical herniated disc fragment, and (2) intradiscal gas can be expelled through a "ball-valve 


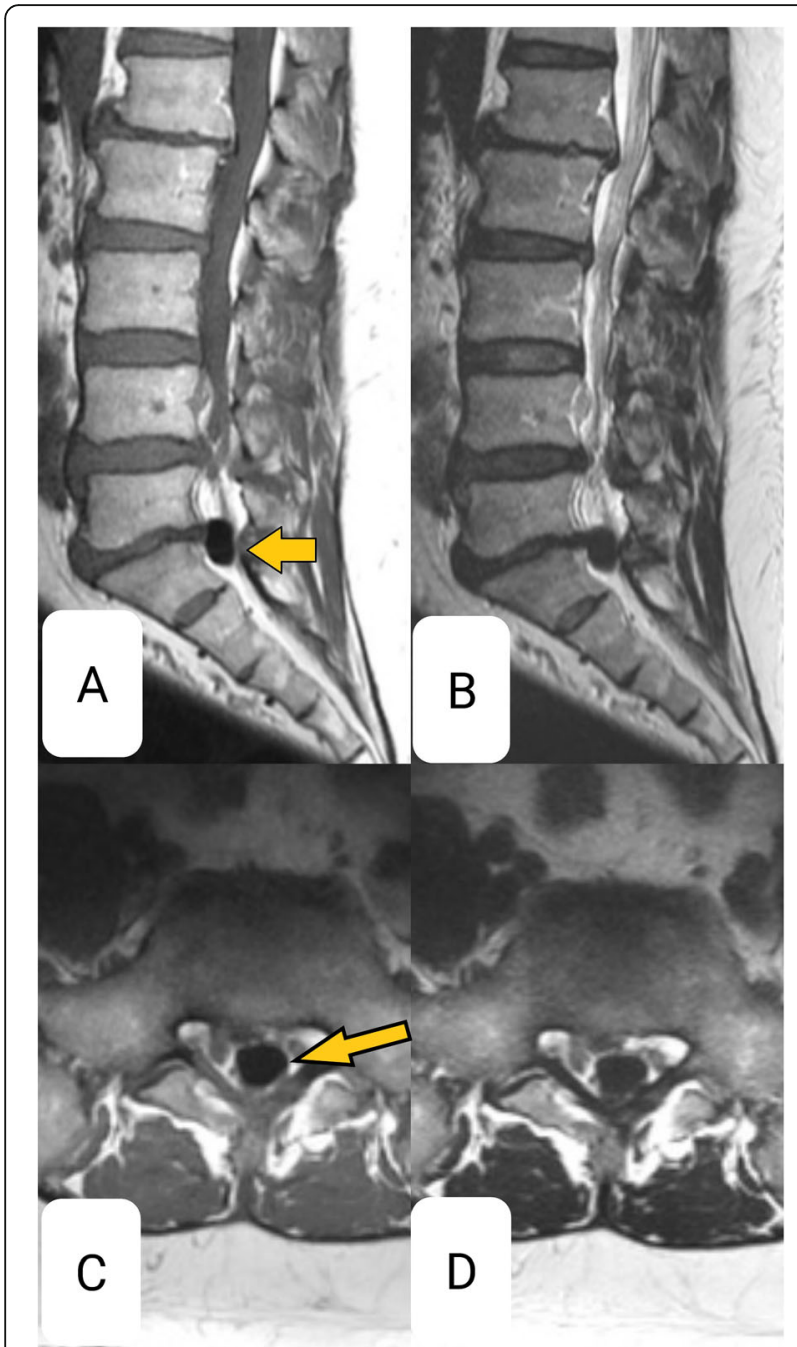

Fig. 2 MRI. Sagittal T1 (a) and T2 (b) and axial T1 (c) and T2 (d) weighted sequences show low-intensity signal in all the sequences in the epidural space compressing the cauda equina. Attenuated CSF signals seen in the spinal canal. Degenerative changes seen in multiple levels. Origin: @ Department of Radiology, King Salman Hospital, Riyadh, Kingdom of Saudi Arabia, 2020

effect" into the epidural space through a weak spot in the annulus fibrosus due to degeneration $[5,6]$. This is facilitated by spine movements which squeeze the disc, producing the necessary pressure gradient for gas migration [5]. These two are differentiated from each other as gas in the herniated disc assumes the contour of the fragment it is contained within, whereas a purely gaseous cyst conforms to the shape of the epidural space [5]. Although gascontaining herniated disc fragments are more common, there appears to be an increasing prevalence in purely gaseous collections in the epidural space in aging populations; this can be attributed to an increasing prevalence of degenerative disc disease producing VP. In either case, the clinical manifestations are identical to real hernias. Therefore, regarding patient management, all should be approached similarly [5].

Conversely, intraspinal air can also be produced from an air-filled facet cyst. If intraspinal gas originates from VP of the disc spaces, air is localized in the anterior epidural space because of the anatomic proximity [7]. If the gas is derived from an air-filled facet, it is observed adjacent to the facet, appearing as an epidural mass next to a degenerated spinal facet joint [7].

Since PR is usually asymptomatic and has protean manifestations, imaging is necessary for a diagnosis [4]. CT, the investigation of choice, reliably shows degenerative changes, osteophytes, disc calcifications, vacuum phenomenon, and PR [4-6]. Additionally, disc density is used to exclude a purely gaseous collection. MRI is less beneficial in spontaneous PR as gas shows low-intensity signals, making it hard to distinguish from calcifications which are also of low-intensity signals on all MR sequences [6]. However, this diagnostic modality can help demonstrate neural and cauda equina compressions as well as identify any underlying lesions.

A conservative management approach has been recommended since PR is generally self-resolving, with air being absorbed directly into the blood spontaneously and completely without recurrence $[4,7]$. Initially, treatment consists of bed rest, a nonsteroidal anti-inflammatory agent, and a muscle relaxant $[4,5]$. If needed, a CT-guided needle aspiration can be performed to transiently relieve symptoms. However, radicular symptoms will recur since the etiology of PR has not been treated; a surgery removing intraspinal gas as well as the disc is required $[5,6]$.

In our case, intraspinal air did not reabsorb spontaneously; rather, it enlarged, exacerbating the existing radicular symptoms (sciatica). This finding, from our review of the literature, has not yet been described.

\section{Conclusion}

Pneumorrhachis is a rare, but important entity as it accompanies a multitude of etiologies and clinical manifestations. Traumatic PR necessitates that the radiologist search for other pathological conditions, especially if intraspinal air is localized in the subdural or subarachnoid spaces (internal PR).

In the case presented here, PR developed spontaneously manifesting as neurological deficits. There were no traumatic or iatrogenic procedures to explain what caused pneumorrhachis; also, spontaneous PR is very rarely symptomatic. Imaging findings suggest that air trapped inside the intervertebral disc (VP) secondary to age-related degenerative changes was responsible. Air was likely expelled out through a weakness in the annulus fibrosus, facilitated by motion of the spine. Therefore, we propose that spontaneous PR accompanying the vacuum disc phenomenon be considered in the differential for radicular symptoms, especially with increasing age. 


\section{Abbreviations}

MRI: Magnetic resonance imaging; CT: Computed tomography;

PR: Pneumorrhachis; VP: Vacuum phenomenon; NSAID: Nonsteroidal anti-

inflammatory agent

\section{Acknowledgements}

None.

\section{Authors' contributions}

A.S and H.M.F.M contributed to the work up and draft of the manuscript. S.S and S.S.U.I contributed to the proofreading and finalization of the

manuscript; S.S.U.I provided the patient information and imaging findings as well as their interpretation. All authors have read and approved the manuscript.

\section{Funding}

This study had no funding from any resource.

\section{Availability of data and materials}

The datasets used and/or analyzed during the current study are available from the corresponding author on reasonable request.

\section{Ethics approval and consent to participate}

Ethical approval is not required for the publication of isolated case reports. The patient was informed about the procedure, and written informed consent was obtained.

\section{Consent for publication}

Written informed consent was obtained from the patient for publication of this case report and accompanying images.

\section{Competing interests}

All authors declare that they have no competing interests.

\section{Author details}

${ }^{1}$ College of Medicine, Alfaisal University, Riyadh, Kingdom of Saudi Arabia. ${ }^{2}$ Medical College, Aga Khan University, Karachi, Pakistan. ${ }^{3}$ Department of Radiology, King Salman Hospital, Riyadh, Kingdom of Saudi Arabia.

Received: 21 August 2020 Accepted: 9 October 2020

Published online: 20 October 2020

\section{References}

1. Goh BKP, Yeo AWY (2005) Traumatic pneumorrhachis. J Trauma - Inj Infect Crit Care 58:875-879 https://doi.org/10.1097/01.TA.0000158249.77176.9A

2. Chaichana KL, Pradilla G, Witham TF, Gokaslan ZL, Bydon A (2010) The clinical significance of pneumorachis: a case report and review of the literature. J Trauma - Inj Infect Crit Care 68:736-744 https://doi.org/10.1097/ TA.0b013e3181c46dd3

3. Yaginuma K, Watanabe M, Saito Y, Takahashi N, Ohara Y, Kobayashi S et al (2019) Pneumorrhachis in children: a report of two cases and review of the literature. Radiol Case Reports 14:1325-1329 https://doi.org/10.1016/j.radcr. 2019.08.010

4. Oertel MF, Korinth MC, Reinges MHT, Krings T, Terbeck S, Gilsbach JM (2006) Pathogenesis, diagnosis and management of pneumorrhachis. Eur Spine J 15 https://doi.org/10.1007/s00586-006-0160-6

5. Coulier B (2004) The spectrum of vacuum phenomenon and gas in spine. J Belg Radiol 87:9-16

6. Kakitsubata Y, Theodorou SJ, Theodorou DJ, Yuko M, Ito Y, Yuki Y et al (2009) Symptomatic epidural gas cyst associated with discal vacuum phenomenon. Spine (Phila Pa 1976) 34:E784-E789 https://doi.org/10.1097/ BRS.0b013e3181b35301

7. Song KJ, Lee KB (2009) Spontaneous extradural pneumorrhachis causing cervical myelopathy. Spine J 9 https://doi.org/10.1016/j.spinee.2008.01.011

\section{Publisher's Note}

Springer Nature remains neutral with regard to jurisdictional claims in published maps and institutional affiliations.

\section{Submit your manuscript to a SpringerOpen ${ }^{\circ}$ journal and benefit from:}

- Convenient online submission

- Rigorous peer review

- Open access: articles freely available online

- High visibility within the field

- Retaining the copyright to your article

Submit your next manuscript at $\boldsymbol{\nabla}$ springeropen.com 